\title{
Acknowledgements and greetings from the Editor-in-Chief
}

Published online: 17 December 2010

(C) Springer-Verlag 2010

As Editor-in-Chief of Applied Microbiology and Biotechnology, I would like to gratefully acknowledge the contributions of all editors and reviewers, who were engaged for Applied Microbiology and Biotechnology in 2010. These thanks for evaluating manuscripts refer in particular also to colleagues who are not members of the editorial board. Their time-consuming services are greatly appreciated, and their expertise and the valuable criticism on the content and style of the submitted manuscripts contributed very much to maintain the high standards of the journal. I would also like to thank the international editors of the journal for their continuing support, thereby ensuring the high quality of the journal and its further increase. These all ensure that the aim of Applied Microbiology and Biotechnology is maintained to communicate significant research documents by presenting accurate, ambitious data in an easily readable form.

The very encouraging development of Applied Microbiology and Biotechnology continued also in 2010. By the end of December 2010, we will have received more than
2,200 manuscripts; this is more than ever before, and some of the biweekly published issues were really voluminous. All signs indicate that the number of high quality manuscripts will further increase in the next year. The impact factor of the journal for this year has sharply increased from 2.569 in 2009 to 2.896 in 2010 , and I predict a further significant increase for the next year. In about 6 months, we will know!

Applied Microbiology and Biotechnology has also again become faster. Nevertheless, we will continue our efforts to further reduce the time required for handling the peer review of manuscripts. In this context, I have to acknowledge the engagement and perfect management of the journal by the Managing Editor, Dorothea Kessler.

Thanking you all very much for your continuous support of Applied Microbiology and Biotechnology; I wish you relaxing holidays, a Merry Christmas and the very best for your health and success in research in the upcoming year.

Happy New Year!

Münster, December 2010 